\title{
Biogeography of arbuscular mycorrhizal fungal spore traits along an aridity gradient, and responses to experimental rainfall manipulation
}

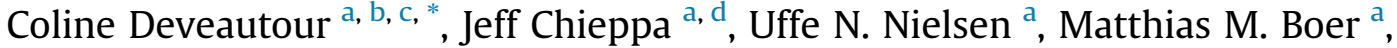 \\ Christopher Mitchell a, Sebastian Horn ${ }^{a}$, Sally A. Power ${ }^{a}$, Alberto Guillen ${ }^{\mathrm{e}}$, \\ Alison E. Bennett ${ }^{\mathrm{f}}$, Jeff R. Powell ${ }^{\text {a }}$ \\ ${ }^{a}$ Hawkesbury Institute for the Environment, Western Sydney University, Penrith NSW, 2751, Australia \\ ${ }^{\mathrm{b}}$ National University of Ireland, Galway, Ireland \\ ${ }^{\mathrm{c}}$ Teagasc, Environment Research Centre, Johnstown Castle, Ireland \\ ${ }^{\mathrm{d}}$ Department of Biology, University of Florida, 1 UNF Drive, Jacksonville, FL, 32224, USA \\ e ERIBiotecMed and Department of Plant Biology, University of Valencia, Burjassot, 46100, Spain \\ ${ }^{\mathrm{f}}$ Dept. of Evolution, Ecology, \& Organismal Biology, The Ohio State University, 318 W. 12th Ave, 300 Aronoff Laboratory, Columbus, OH, 43210, USA
}

\section{A R T I C L E I N F O}

\section{Article history:}

Received 26 March 2019

Received in revised form

15 November 2019

Accepted 19 November 2019

Available online $\mathrm{xxx}$

Corresponding Editor: Thomas W. Crowther

\section{Keywords:}

Arbuscular mycorrhizal fungi

Aridity

Community assembly

Fungal traits

Melanin

Spore colour

Spore morphology

Spore size

\begin{abstract}
A B S T R A C T
Spore size, colour and melanin content are hypothesised to be functional in relation to environmental stress. Here, we studied AM fungal spores in arid environments of Australia and in an experimental platform simulating altered rainfall. We used microscopy and image analysis to measure spore colour and size, and a quantitative colorimetric assay to estimate melanin content in spores. In arid sites, melanin content tended to increase with increasing aridity. We observed a large range of spore colours at all sites but found a higher proportion of both dark and light spores, and fewer intermediate colours, in drier sites. Spore abundance and size varied among sites, but neither were related to aridity. In the experimental platform established in a grassland, we found no evidence that altered rainfall influenced spore traits. This study identifies traits associated with environmental stress to inform future work into AM fungal life history and assembly processes.
\end{abstract}

๑) 2019 Elsevier Ltd and British Mycological Society. All rights reserved.

\section{Introduction}

Arbuscular mycorrhizal (AM) fungi form obligate symbiotic associations with plants and contribute to their defence against environmental stress including drought (Augé, 2001). This is particularly important in the current context of climate change, where climatic scenarios project a general reduction in rainfall amounts in mid-latitudes and sub-tropical dry regions (IPCC, 2014). A few studies have attempted to address how AM fungal communities will respond to changes in rainfall patterns. Field studies addressing this question using microscopy methods have shown

\footnotetext{
* Corresponding author. Hawkesbury Institute for the Environment, Western Sydney University, Penrith NSW, 2751, Australia.

E-mail address: coline.deveautour@nuigalway.ie (C. Deveautour).
}

that changes in rainfall patterns alter the proportion of root length colonised by AM fungi (Staddon et al., 2003; Martínez-García et al., 2012) and spore abundance and community composition (Sun et al., 2013), whereas studies relying on DNA sequencing techniques have shown that AM fungal community structure and composition are affected by rainfall, but with a major proportion of the variation in the community composition remaining unexplained (Li et al., 2015; Deveautour et al., 2018). The high variability observed in molecular community data may be masking the effects of changes in the environment on AM fungi community assembly (Hart et al., 2016), which makes predicting AM fungal responses to climate change difficult and limits our understanding of the mechanisms underlying how AM fungal communities are structured by precipitation regimes.

Recently, a trait-based approach has been suggested in fungal 
ecology as a way to test evolutionary trade-offs between traits and environmental conditions, to quantify functional diversity and to understand community assembly (Chagnon et al., 2013; AguilarTrigueros et al., 2014; Treseder and Lennon, 2015). This approach has been extensively used in plant studies to identify functional traits and understand how they vary along environmental gradients as a way to predict community responses to climate change (De Valpine and Harte, 2001; Lin et al., 2010; van Ommen Kloeke et al., 2012). Therefore, using a trait-based approach might improve our understanding of how precipitation regimes affect AM fungal communities, and the ability to predict fungal responses to climate change. Examining the relevant set of ecologically important traits in fungal communities could improve our understanding of AM fungal community assembly because we expect that taxa are filtered into local communities according, in part, to their traits and to environmental conditions.

Spores are AM fungal propagules involved in dispersal and persistence (Peterson et al., 2004), and thus represent a key life history stage for colonisation and survival within stressful environments. AM fungal spores can enter dormancy, a resting state where metabolism is reduced to remain viable for a period of time before germination takes place, due to endogenous inhibitors (endogenous dormancy; Tommerup, 1983, 1985) or to external conditions (exogenous dormancy; Souza, 2015). AM fungal dormant spores can be found in a variety of soils and ecosystems, and can germinate once under favourable conditions (Souza, 2015). Spores have very diverse characteristics that have been used for identification of AM fungal species, but traits also vary within a single species. The most strikingly variable traits are their size, which ranges mostly from 40 to $500 \mu \mathrm{m}$ in diameter, and their colour (from hyaline, white, to an array of colours from yellow to red, brown to black) (Souza, 2015; International culture https:// invam.wvu.edu/, 2018; Aguilar-Trigueros et al., 2019). The colour of a spore can also change as it matures (Souza, 2015). These traits have been well studied for taxonomic purposes, but very little is known about their ecological significance. Intra- and inter-specific variation in spore traits can be expected to have functional importance where one or a combination of traits are likely to influence the survival and dispersal of spores and, ultimately, AM fungal community assembly.

Here, we studied fungal spore abundance and spore traits hypothesised to be related to environmental stress to identify ecologically relevant traits involved in AM fungal response to reduced rainfall amounts. Spore abundance at the species level is hypothesised to be associated with sporulation and survival rates of AM fungi (Bever et al., 1996). Sporulation events require favourable environmental conditions, such as high available soil moisture that is also optimal for their host development (reviewed in Augé, 2001). It has been observed that spore production, while stimulated during a short-term drought period, is lower in arid ecosystems compared to more mesic environments (Augé, 2001). However, Liu et al. (2009) found that within arid sites, spore abundance was negatively correlated with soil moisture.

Spore survival might depend on a set of particular traits. To our knowledge, few studies have been conducted on how environmental stress influences fungal spore traits, and none of these have been conducted on AM fungal spores. In other fungal groups, spore size is expected to influence fungal species' capacity to disperse (Hussein et al., 2013) and to survive. It has been hypothesised that larger spores contain more nutrients and water reserves, possibly improving their ability to germinate in stressful environments, while smaller spores may be more prone to exogenous dormancy and thus require favourable environmental conditions to germinate (Davet, 2004; Halbwachs and Bässler, 2015). In addition, compounds responsible for pigmentation exhibit protective properties in other fungal groups (Ruiz-Herrera, 2012; Cordero et al., 2018). One of these pigments is melanin, which produces dark colours, mainly brown and black. This compound, produced in the cell wall, provides structural strength and is recalcitrant to degradation. It has been studied extensively for its properties in pathogenesis and environmental protection in pathogenic fungi, such as tolerance to extreme temperatures, enzymatic lysis and UV light (reviewed in Henson et al. 1999; Jacobson, 2000). Melanin is also involved in drought resistance in an ectomycorrhizal fungus (Fernandez and Koide, 2013).

Our aim was to assess the relationship between AM fungal spore traits and rainfall regimes to identify traits involved in fungal survival under stressful environments. We first evaluated spore abundance as a proxy for sporulation and spore survival of the whole fungal community, expecting lower densities in drier environments where water limitations likely suppress sporulation. We further expected a shift in the distribution of spore size in drier environments. If small spores predominate in drier environments, it may indicate that dormancy is an important strategy to survive stressful periods until conditions become favourable for germination (dormancy hypothesis). Conversely, if larger spores are more abundant in drier environments, it may indicate that nutrients and water reserves within the spore are required to survive and to germinate under stressful conditions (storage hypothesis). We also predicted that spore communities from drier environments would have a higher melanin content because of its protective properties (reviewed in Henson et al. 1999; Jacobson, 2000). Therefore, we expected that spores from those environments would be on average darker with a low proportion of light-coloured spores. To assess long-term effects of climate on AM fungal spore traits, we evaluated communities from multiple arid sites experiencing different long-term, historical climatic conditions. To assess the potential for communities to shift as a result of extreme climate shifts, we also studied AM fungal spore traits in communities exposed to two years of experimentally reduced rainfall in replicated field plots. We extracted AM fungal spores from soil and used microscopy and image analyses to determine spore abundance, colour and size, and a quantitative colorimetric assay to estimate melanin content.

\section{Materials and methods}

\subsection{Field sites and experimental design}

We assessed spore traits in two different experimental systems. To study spore traits in communities exposed to long-term rainfall conditions, samples were collected from experimental platforms established in September 2016 in arid sites of New South Wales and Queensland, Australia. This study was set up to evaluate how past rainfall shapes Australian dryland ecosystems and their response to altered rainfall regimes. Six arid sites were selected to represent an aridity gradient, along a northern and a southern transect that differed in intra-annual rainfall variability (location and description of the sites in Fig. 1). The vegetation and soil properties were very different across all arid sites (Table S1), but briefly Broken Hill is a sclerophyllous shrubland dominated by Maireana pyramidata, Cobar and Nyngan are open woodlands, Milparinka is a grass community dominated by Astrebla lappaceae and Astrebla pectinata and Quilpie and Charleville are mulga and eucalypt woodlands dominated by Acacia aneura var aneura. In addition, the soil in Broken Hill is brown calcareous sand, Cobar and Nyngan have red soil, clay with gravel, Milparinka has grey clay, Quilpie has red clay and Charleville has red sandy soil. The aridity index (AI) was calculated as the ratio of mean annual potential evapotranspiration and mean annual precipitation (i.e. higher values equal greater 


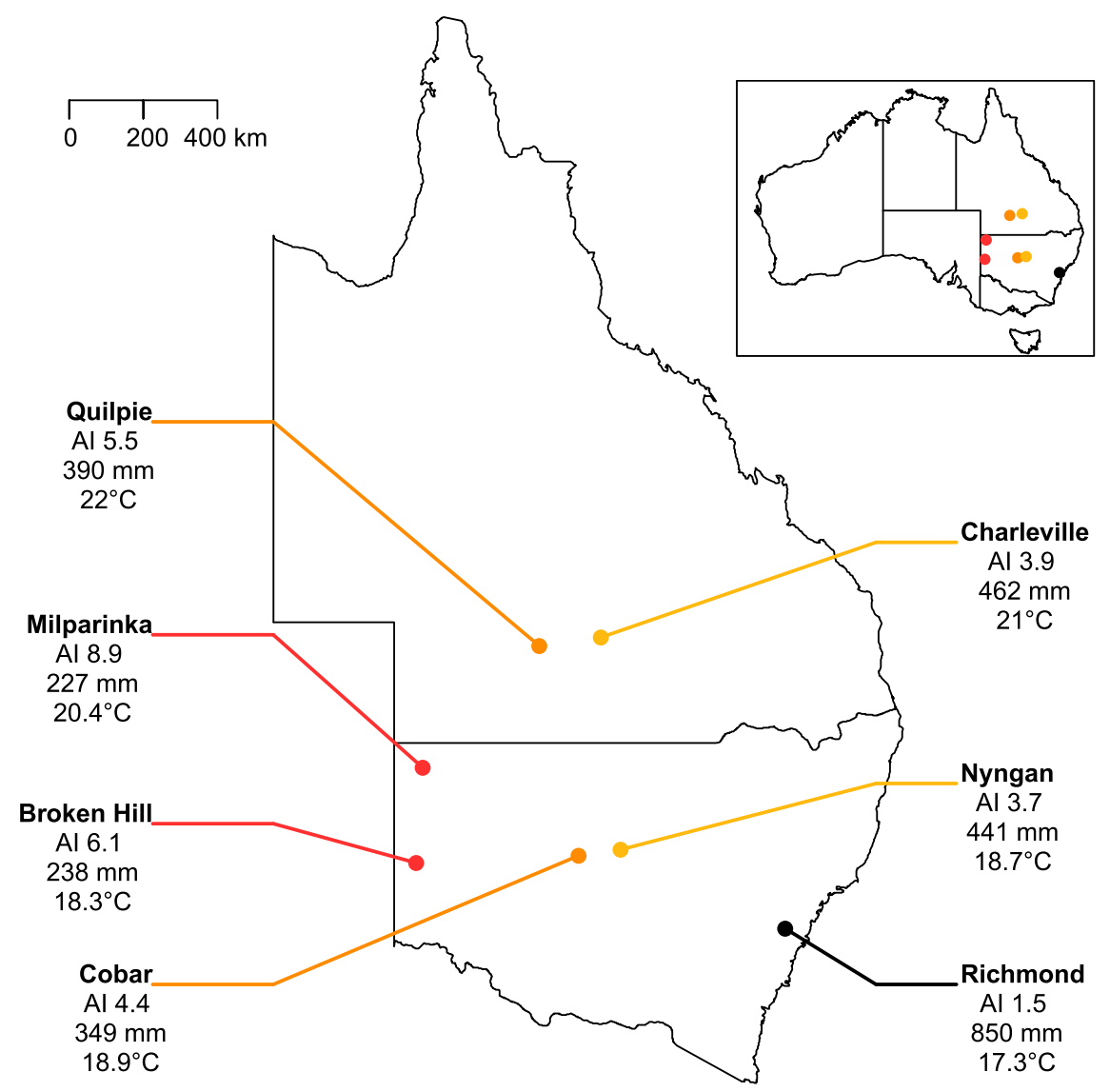

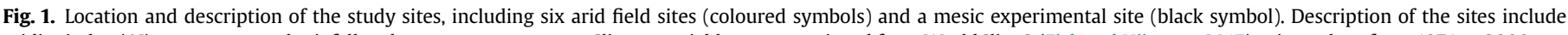

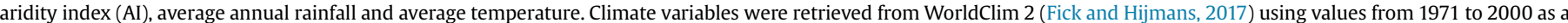

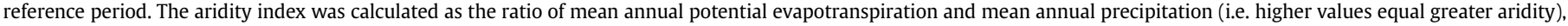

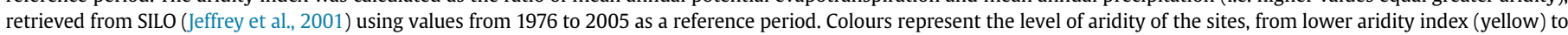
higher aridity index (red)

aridity), with climate data retrieved from SILO (Jeffrey et al., 2001) using values from 1976 to 2005 as a reference period. AI ranged from 3.7 to 8.9 across the six sites. Samples were collected at two time points (September 2016; April 2017) to assess whether there was temporal variation. Each arid site had three replicates, yielding a total of 36 samples. At each sampling period and at each site, soil samples of approximately $100 \mathrm{~g}$ each were collected from the top $10 \mathrm{~cm}$ and dried at $40{ }^{\circ} \mathrm{C}$. The minimum distance between plots within each arid site was $3 \mathrm{~m}$ and the maximum was $21 \mathrm{~m}$.

To study traits of spores exposed to extreme changes in rainfall regimes, we collected samples from the 'Drought and Root Herbivore Impacts on Grasslands' (DRI-Grass) experiment. This experiment is located in a grassland (list of most abundant plant species in Table S2; Power et al., 2016) at the Hawkesbury Campus of Western Sydney University in Richmond, NSW, Australia, where the aridity index is 1.5. DRI-Grass is described in Power et al. (2016), but very briefly, it was established in 2013 and consists of $2 \mathrm{~m} \times 2 \mathrm{~m}$ plots covered with shelters that exclude natural rainfall and have automated, controlled application of water underneath the shelters. From this experiment, we collected samples from three watering treatments: (1) control (ambient rainfall), (2) reduced (50\% less rainfall than ambient), and (3) summer drought (total rainfall exclusion from December to March). Each treatment consists of six replicates, for a total of 18 soil samples. The minimum distance between sampled plots was $2 \mathrm{~m}$ and the maximum distance was $36 \mathrm{~m}$. Eight soil cores of $2 \mathrm{~cm}$ diameter were collected from the top
$10 \mathrm{~cm}$ of each plot, and bulked to the plot level before drying at $60{ }^{\circ} \mathrm{C}$ overnight. Soil samples were collected in March 2015, 22 months after rainfall manipulation began, because of a clear gradient in soil moisture present between treatments at that time (Fig. S1).

\subsection{Spore extraction}

The dried soil samples were kept at ambient temperature until spore extraction. Spores were extracted from a volume of $10 \mathrm{~cm}^{3}$ of soil (between 12 and $15 \mathrm{~g}$ ) using the sucrose centrifugation and wet sieving method. Briefly, $25 \mathrm{~mL}$ of $60 \%$ sucrose solution was added to each soil sample and mixed well before centrifugation at $1046 \mathrm{~g}$ for 5 min (Thermo Scientific, Fiberlite F15-8x50cy, USA). Spores were recovered from the suspension by pouring the liquid through a sieve with $500 \mu \mathrm{m}$ opening on top of a sieve with $38 \mu \mathrm{m}$ opening, and rinsed for 2 min with water to remove the sucrose. We verified, using a stereomicroscope, that no spores remained on the top sieve. The great majority of spores from other fungal groups are smaller than AM fungal spores and are, therefore, excluded during the sieving and rinsing step. Based on their morphology, most spores were identified as Septoglomus sp. and Diversispora sp., although some belonging to the Gigasporaceae were also observed.

The filtrate collected on the bottom sieve was transferred to a Petri dish to calculate spore abundance. Intact spores were then 
separated manually from detritus using an adjustable pipette to evaluate other traits. To ensure a representative random subsample for all subsequent measurements, the Petri dish was rotated and agitated to distribute spores randomly in the plate. We then collected all the spores present in half the Petri dish, proceeding horizontally from the top to the centre of the plate. From those collected spores, a subsample was used to determine colour and size, and another subsample was used to evaluate melanin content. Spore abundance and melanin content were determined in samples collected in Richmond in 2015 and arid sites at both time points (2016 and 2017); spore size and colour were evaluated for Richmond in 2015 and only in 2017 for the arid sites, because we did not collect images of spores isolated from the 2016 samples.

\subsection{Spore abundance}

To calculate spore abundance, the Petri dish was randomly rotated and agitated before counting spores in 10 fields of $0.5 \mathrm{~cm}^{2}$ under an Olympus SZ61 stereomicroscope. We obtained the average number of spores per field before multiplying by the area of the Petri dish to estimate the number of spores in the plate. The number of intact spores per gram of dry soil was calculated by dividing the number of spores in the Petri dish by the weight of the soil sample from which the spores were extracted.

\subsection{Spore size and colour}

To analyse the colour and size of the spores, we photographed samples containing 30 to 60 spores for each soil sample using a Leica MZ12 stereomicroscope (Wetzlar, Germany) and an attached JVC Digital Camera KY-F1030 (JVCKENWOOD, USA). Spores were photographed on the same day of the extraction in Petri dishes containing water. The pictures were taken under the same light conditions, using a grey background $(R=167, G=165, B=142)$, at $51.2 \times$ magnification.

The pictures were then analysed using an interactive, custom function that we developed (https://bitbucket.org/jrpowell/ sporetraits) for image processing in R ( $\mathrm{R}$ core Team, 2018; these analyses were performed using version 3.2.5). After loading each image, the function requests the user to locate the four corners of the image, which defines the location of the image in the figure region and the coordinate system of the graphics window. These coordinates are used to relate the coordinate system to the absolute length and width of the image, calibrated using a photograph of a stage micrometre under the same magnification. For spore measurements, the user selects two points at the margins of a spore along both its longest axis and its shortest axis; the function then converts these vectors of coordinates into measures of spore length and width (in $\mu \mathrm{m}$ ). Colour metrics (RGB model) were obtained by identifying pixels under the longest and shortest axis of the spore, from the same coordinate vectors used to calculate length and width, extracting values in these pixels from the red, green and blue colour channels scale, and calculating the average and standard deviation for each channel.

The projected surface area for each spore was then calculated using the following formula: $4^{*}$ (length/ $\left./ 2\right)^{2 *} \pi$, and the volume was calculated using: $4 / 3{ }^{*} \pi *$ (length $\left./ 2\right)^{3}$. The amount of black $(K)$ in each spore was calculated: $1-(\max (R, G, B) / 255)$. Formulas presented in Hanbury (2003) were used to convert RGB into HSL metrics (hue, saturation, luminance); luminance $=0.2126^{*} \mathrm{R}+0.7152^{*} \mathrm{G}+0.0722^{*} \mathrm{~B}$; saturation $=\max (\mathrm{R}$, $\mathrm{G}, \mathrm{B})-\min (\mathrm{R}, \mathrm{G}, \mathrm{B})$; and hue was calculated using the following formula:

$$
\begin{aligned}
& H^{\prime}=\arccos \left[\frac{R-\frac{1}{2} G-\frac{1}{2} B}{\left(R^{2}+G^{2}+B^{2}-R G-R B-B G\right)^{\frac{1}{2}}}\right] \\
& H=\left\{\begin{array}{cc}
360^{\circ}-H^{\prime} & \text { if } B>G \\
H^{\prime} & \text { if } B<G
\end{array}\right\}
\end{aligned}
$$

Hue is the colour of the sample, expressed in degrees $\left(0^{\circ}\right.$ to $360^{\circ}$ ), saturation is intensity of the colour (where 0 is grey and 1 is colour), and luminance is a scale of dark (where 0 is black and 1 is white) and it differs from $\mathrm{K}$ in that it accounts for the light source of the three colours while K considers only the colour that appears the lightest. For each picture, we estimated the size and colour of 20-to35 spores, selected randomly by placing a grid over the image. In total, we obtained spore size and colour metrics for 1125 spores: 552 sampled from the arid sites and 575 from Richmond.

\subsection{Melanin content}

We used a quantitative colorimetric assay to estimate the average concentration of melanin in the spore community (Butler and Lachance, 1986). The Azure A dye used for this assay binds strongly with melanin; therefore, this test relies on the quantification of the dye absorbance with or without exposure to melanin. The dye is prepared by dissolving $0.1 \mathrm{~g}$ of Azure A (\#861049, SigmaAldrich) in $5 \mathrm{~mL}$ of $0.1 \mathrm{M} \mathrm{HCl}$. The dye is then diluted in water until obtaining an optical density of approximately 0.65 at $610 \mathrm{~nm}$ using a spectrophotometer (CLARIOstar, BMG Labtech, Germany). The standard curve was generated by exposing $3 \mathrm{~mL}$ of Azure A dye to 0.1-0.5 mg of synthetic melanin (\#M8631, Sigma-Aldrich), weighed on a microbalance XP6 (Mettler Toledo, AU) to obtain the absorbance corresponding to a known concentration of melanin $(\mathrm{mg} / \mathrm{mL})$. The absorbance of the dye was measured in the spectrophotometer at $610 \mathrm{~nm}$ after $90 \mathrm{~min}$ at ambient temperature and in the dark. The tubes containing the dye and the melanin were inverted three times at $0 \mathrm{~min}, 45 \mathrm{~min}$ and $90 \mathrm{~min}$, to optimize melanin exposure to the dye.

The same protocol was applied to the samples to determine melanin content in the spore community. Samples containing between 100 and 150 spores were dried overnight at $60{ }^{\circ} \mathrm{C}$. The melanin concentration was obtained by exposing the dried spores to $0.3 \mathrm{~mL}$ of Azure A dye for $90 \mathrm{~min}$ in the same conditions as the standard curve samples before measuring the absorbance at $610 \mathrm{~nm}$. Melanin concentration in each sample was calculated based on the standard curve, and then multiplied by the Azure A volume to obtain the weight of melanin $(\mu \mathrm{g})$ in the sample. For each sample, the average amount of melanin per spore was obtained by dividing the melanin content $(\mu \mathrm{g})$ between the number of spores present in the sample. To account for the effect of the spore size on the community melanin content, we estimated the melanin content relative to the average spore area $\left(\mu \mathrm{g} / \mu \mathrm{m}^{2}\right)$ of each sample. For this latter analysis, we used spore surface area because melanin is produced in the cell wall, and we only considered samples for which spore size was measured (Richmond samples collected in 2015 and the arid sites collected in 2017).

\subsection{Statistical analyses}

All analyses were performed in $\mathrm{R}$ version 3.2.5 ( $\mathrm{R}$ Core Team, 2018). The $\log _{10}$ transformation was applied to projected spore volume prior to analysis in order to normalise residual variation. Aridity indices were $\log _{10}$-transformed prior to use in statistical models to account for the fact that variation in aridity among sites 
was not normally distributed. In all cases except spore density (see results), the outcomes of statistical tests were not dependent on transformation of the aridity index.

To visualise multivariate patterns in community-averaged spore traits across all sites, and to estimate the extent that site explained variation in these multivariate patterns, we first calculated an aggregate average of projected spore volume, hue, luminance, saturation and amount of black colouration $(\mathrm{K})$ for the spore community of each soil sample. All traits, including melanin content and spore abundance, were then standardized to a constant mean and variance using the decostand function in the vegan package (Oksanen et al., 2018). We then assessed the amount of variation in community traits explained by the sites using Redundancy Analyses (RDA) with the rda function (vegan). This analysis was performed using data collected from the arid sites in 2017 and from Richmond (2015).

We then evaluated how each trait individually varied in response to variation in rainfall. To evaluate whether the aridity gradient affected spore traits, we used polynomial models testing linear and quadratic effects. We included latitude as a co-variate to account for other environmental factors (e.g., temperature) possibly also influencing spore traits. In separate models, we tested the main effect and interaction between the aridity and sampling date (2016 and 2017), and the main effect of latitude on spore abundance or on melanin content. We used linear mixed-effects models, with the lmer function (Imer; Bates et al., 2015), modelling 'site' as a random effect to account for the nested sampling design. We used a model simplification approach to avoid overparameterising our models. When we tested spore abundance, we found no evidence that sampling date influenced spore abundance and fitted a new model without this variable. We also found no evidence that latitude influenced melanin content so fitted a new model without this variable. For responses obtained from images and to account for potential variation among images, we modelled 'sample' (one image per sample) nested in 'site' as random effects. Statistical significance was determined using ANOVA (analyses of variance) based on Kenward-Roger approximated degrees of freedom, calculated using Anova from the car package (Fox and Weisberg, 2011). The adequacy of the models was determined by visually examining the residuals for normality and homoscedasticity. We tested for differences in the range for each trait (i.e., trait dispersion) between sites using Bartlett test (bartlett.test function, stats package in R). The difference in variance among southern and northern arid sites was tested using the nonparametric Fligner-Killeen test (fligner.test function, stats package). We explored the spore community colour metrics by plotting the luminance and saturation among the sites with violin plots showing abundance distributions for each colour metric.

For samples collected in Richmond, we tested how spore abundance and melanin content varied among the watering treatments using ANOVA (analysis of variance). We tested the effect of watering treatments on the projected spore volume, luminance and saturation using linear mixed-effects models, modelling 'sample' as a random effect, to account for potential variation among images. We tested for differences in range for each trait between sites using Bartlett test (bartlett.test function, stats package). We performed multiple comparisons using Tukey's test with TukeyHSD function, where appropriate.

Because melanisation is associated with black-brown colouration, we expected that the black signal $(\mathrm{K})$, luminance and saturation would be significantly associated with the melanin content in the community. If so, image analysis could be used to make inferences about melanisation of individual spores; therefore, we evaluated the relationship between each community-averaged colour metric and melanin content. We calculated the average $\mathrm{K}$, luminance and saturation for communities of each soil sample collected in the arid sites in 2017 and in Richmond (2015). We then estimated the correlation between each colour variable and the melanin content either calculated on a per spore basis $(\mu \mathrm{g} /$ spore) or on a per spore area basis $\left(\mu \mathrm{g} / \mathrm{um}^{2}\right)$ in six separate linear models.

\section{Results}

\subsection{Significant geographic patterns in spore trait variation}

We first explored the relationship among community-averaged trait values measured from sampled spores and their distributions across sampled sites. Site explained $60 \%$ of the variation in the spore traits (RDA; $\left.F_{6,29}=7.3, P<0.01\right)$. In general, spores sampled from the experimental platform in Richmond (aridity index $=1.5$ ) were very different from spores collected from arid sites, exhibiting a higher projected spore volume, spore abundance and darker spores (Fig. 2). Therefore, we focused on individual spore traits and how they varied across the arid sites to explore the ecological relevance of these traits in AM fungal communities in response to variation in long-term climate, and present the results of the rainfall manipulation experiment separately.

\subsection{No patterns in spore abundance in relation to aridity nor latitude}

Although we observed variation in average spore abundance among sites ('site' explained approximately one-third of variation), we did not find evidence that spore abundance varied in relation to aridity (linear mixed-effects model; $P=0.37$ ) nor in relation to latitude (linear mixed-effects model; $P=0.40$; Fig. $3 \mathrm{~A}$ ). Spore abundance at the six arid sites was 33\% lower, on average, than observed in Richmond (DRI-Grass).

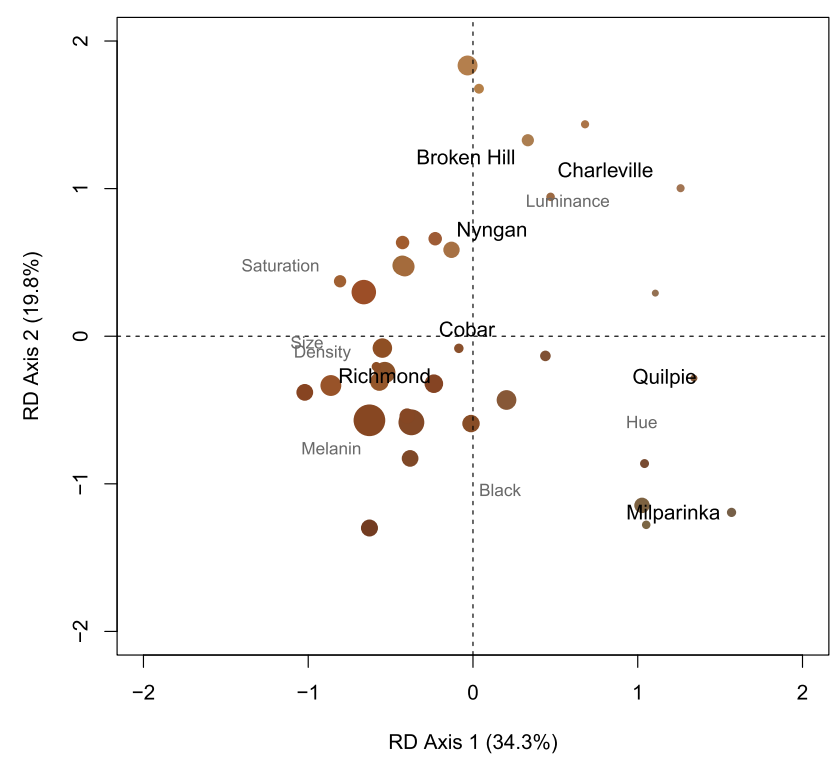

Fig. 2. Constrained RDA ordination showing the spore community trait variation according to sample origin. Each point represents the spore community of a soil sample, and the symbol size and colour reflect weighted averages of projected spore volume (from 215340 to $4394587 \mu^{3}$ ) and of spore colour based on RBG (red, blue, green) colour channels measure, respectively, on the sampled spore community. Small grey labels show spore abundance ('Density') and the traits: spore averaged melanin content ('Melanin') and community averaged projected spore volume ('Size'), amount of black ('Black'), hue ('Hue'), luminance ('Luminance') and saturation ('Saturation'). Other labels are the sites. 

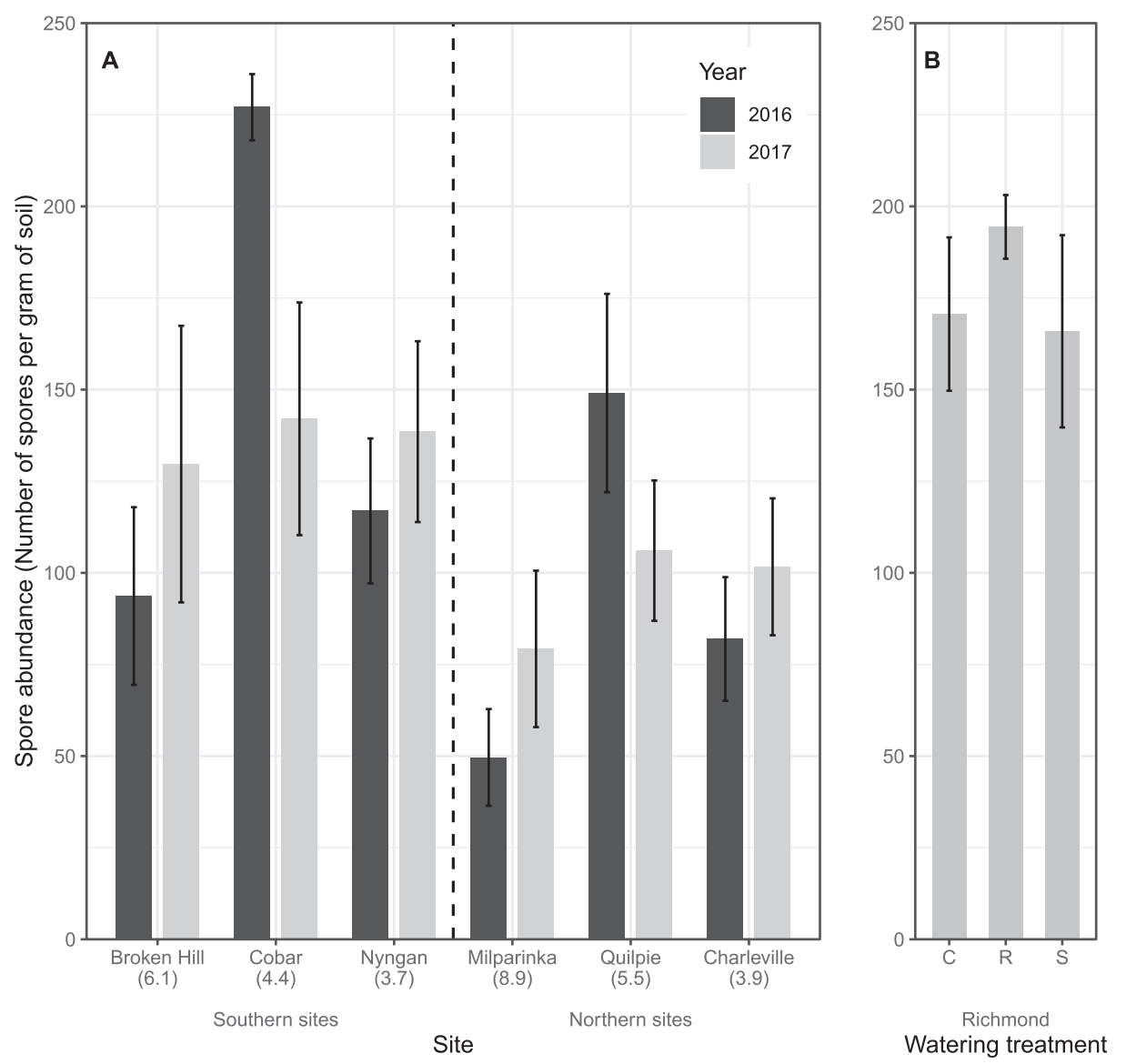

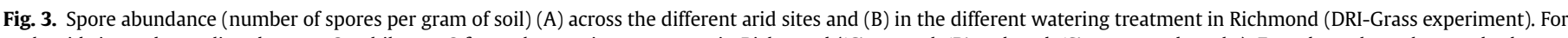

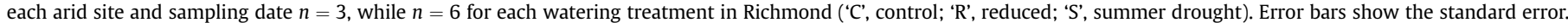
Aridity indices are indicated under the names of each arid site.

\subsection{Latitudinal differences in spore size, but no relation to aridity}

In arid environments, the average projected volume per spore was $504370 \mu \mathrm{m}^{3}$, and ranged from 23649 to $11722939 \mu \mathrm{m}^{3}$ (more than 495 -fold increase in projected volume). The range in projected spore volume was similar among the arid sites (Bartlett test; $P=0.16)$. Spores from the three northern sites were observed to have on average $46.7 \%$ lower projected spore volume than the three southern sites (linear mixed-effects model; $P=0.03$, Fig. 4A). Although there was the appearance of a trend within each transect, we observed no evidence that the spore size varied in relation to the aridity gradient (linear mixed-effects model; $P=0.50$ ). In Richmond (DRI-Grass), the average projected spore volume $\left(1417358 \mu \mathrm{m}^{3}\right.$ ) was higher than observed for arid sites, but with a long tail on the distribution as this site had a wider range (from 54775 to $76002067 \mu \mathrm{m}^{3}$, representing more than a 1380-fold increase; Fig. 4B).

\subsection{Biogeographic patterns in colour saturation (average) and luminance (range)}

To study spore colouration, we based our analyses on luminance and saturation (Fig. 5A) because hue did not reflect spore colouration when luminance and saturation were low (Fig. 5B and C). Nearly $97 \%$ of the spores had a range of hue between $0^{\circ}$ (red) to $60^{\circ}$ (yellow), which are colours to be expected for spores. However, 3\% of the hue values varied between $70^{\circ}$ (green) and $300^{\circ}$ (blue) when low values were observed for luminance (dark colours) and saturation (grey colours).

The average luminance of spores at the arid sites was 0.43 , and ranged from 0.08 to 0.86 . We did not observe significant differences in spore luminance in relation to the aridity gradient (linear mixedeffects model; $P=0.94$ ) nor latitude (linear mixed-effects model; $P=0.90$ ). Spores from Milparinka and Quilpie (8.8 and $5.5 \mathrm{AI}$, respectively) exhibited a higher density of both dark and light spores in their communities (distributions were roughly bimodal), while Broken Hill (6.1) showed a high density of light spores only (Fig. 6A). The range in spore luminance in communities from northern sites was 1.7 times wider than communities from southern sites (Fligner-Killeen test; $P<0.01$ ). Communities from Richmond (DRI-Grass) showed on average a lower luminance (0.35), but presented a low density of both light and dark spores (normal distribution) (Fig. 6B).

The average saturation at the arid sites was 0.33 , and ranged from $<0.01$ to 0.74 . We observed no evidence that communities at those locations varied in relation to the aridity gradient (linear mixed-effect model; $P=0.18$ ) nor in relation to latitude (linear mixed-effect model; $P=0.23$ ). While nearly $75 \%$ of the spores in other sites exhibited saturation values above $0.25,55 \%$ of the spores from Milparinka (AI 8.9) and 46\% of the spores from Quilpie (AI 5.5) were below that value, representing a lower density of intensely coloured spores compared to other sites (Fig. 6C). Communities from Richmond (DRI-Grass) had a higher average saturation (0.4) and had few spores with low saturation (Fig. 6D). 

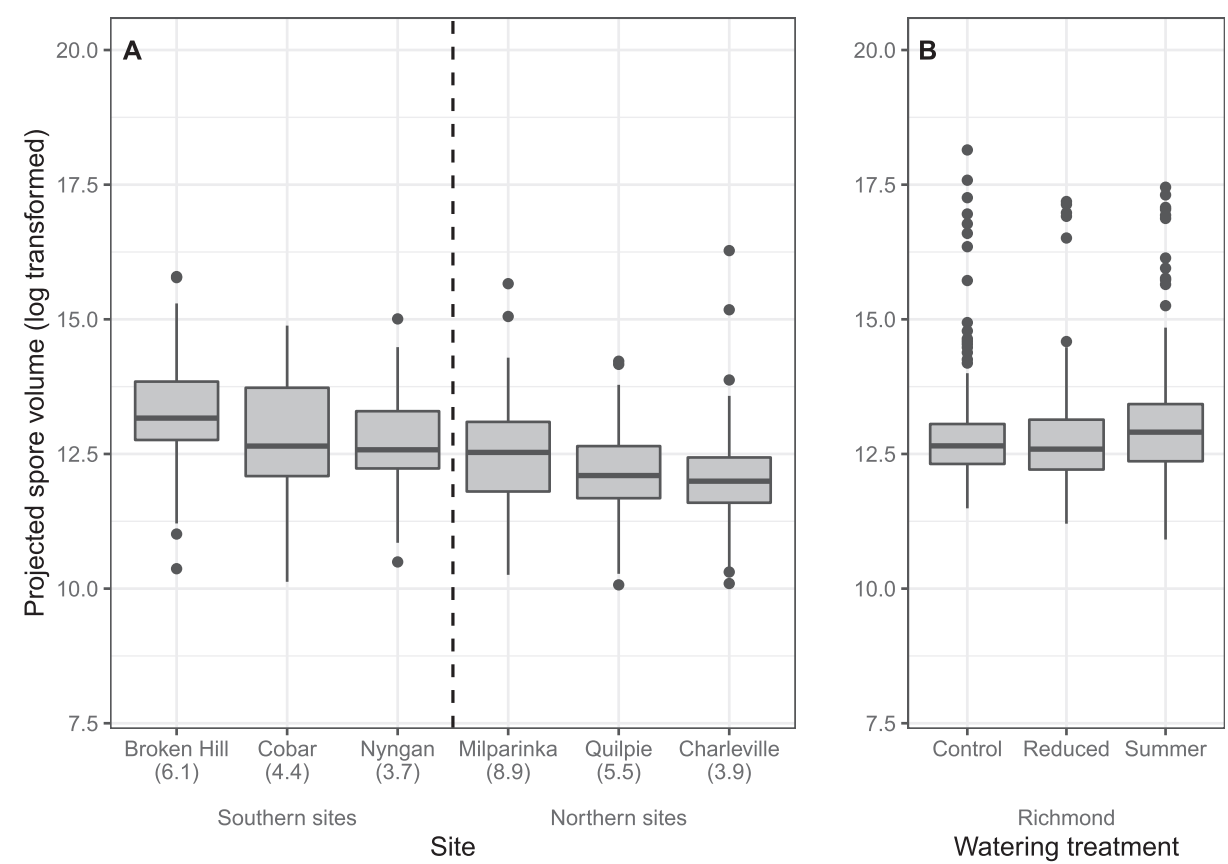

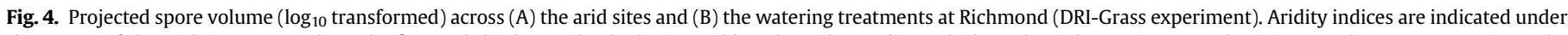

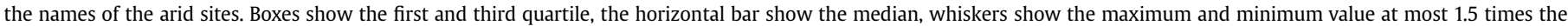
interquartile range, dots show points beyond this range.
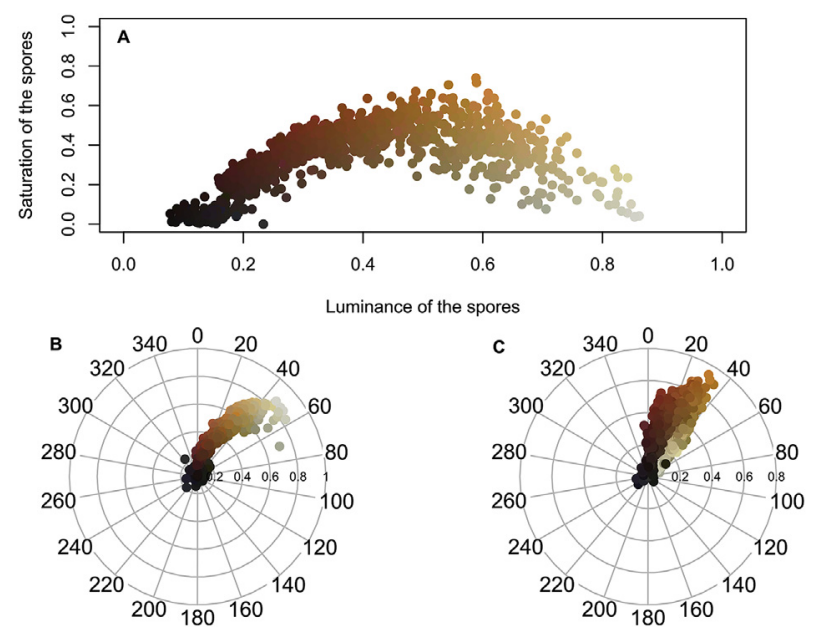

Fig. 5. Spore (A) colouration-based saturation and luminance, and hue values (expressed in degrees) according to (B) luminance or (C) saturation. Each point represents a spore and the symbol colour reflects RBG colour channels measure on the sampled spore.

\subsection{Spore melanin content increases with increasing aridity}

We evaluated the melanin content of the spore communities depending on aridity and, because melanin was assessed for both sampling dates, we also evaluated whether this trait varied between time-points for each community. We observed a marginally non-significant relationship between aridity and melanin content ( $\mu \mathrm{g} /$ spore) (linear mixed-effects model; $P=0.07$ ). Melanin tended to increase with increasing aridity in 2016 but this trend was less evident in 2017 (linear mixed-effects model [aridity and sampling date interaction] $P=0.05$, Fig. 7A). Melanin content per spore was lower, on average, for those sampled in 2017 compared with $2016(P<0.01$;
Fig. 7A). Rainfall, on average, was less during the month leading up to sampling in 2017 than the month prior to sampling in 2016, so this reduction in melanin content does not correspond to an increase in rainfall (Table 1).

Average melanin content per spore appeared to be partly correlated with average spore size (Fig. 2), which also varied among sites (Fig. 4). To account for the effect of spore size when assessing variation among communities in melanin content per spore, we estimated the melanin content per unit of spore area for samples collected in 2017, using the average projected spore area of each sample. When accounting for the size of spores in each community, we did not observe significant differences among the six arid sites (linear mixed-effects model; $P=0.30$ ), nor in relation to latitude $(P=0.52$, Fig. 8 A $)$.

\subsection{Limited responses of spore traits to extreme shifts in rainfall patterns after two years}

In Richmond (DRI-Grass), we found no evidence that experimentally manipulating rainfall for 22 months affected average spore abundance (ANOVA; $F_{2,15}=0.6, P=0.57$; Fig. 3B), luminance (linear mixed-effects model; $P=0.80$; Fig. 6B), saturation (linear mixed-effects model; $P=0.68$, Fig. $6 \mathrm{D})$ or melanisation per spore (ANOVA; $F_{2,15}=0.44, P=0.65$; Fig. $\left.7 \mathrm{~B}\right)$ or per spore area $\left(F_{2,15}=1.3\right.$, $P=0.31$; Fig. $8 \mathrm{~B})$. We observed a marginally non-significant relationship between watering treatment and the spore volume (linear mixed-effects model; $P=0.09$ ).

\subsection{Spore colour measures are weak predictors of melanin content}

Community-averaged luminance was the best predictor of melanin content, explaining $13 \%$ of the variation in average melanin content per spore in each community (linear model; slope $=-0.41$, $P=0.02$; Fig. 9C). We also observed a marginally non-significant relationship between the melanin content per spore and community-averaged saturation, explaining $6 \%$ of the variation 

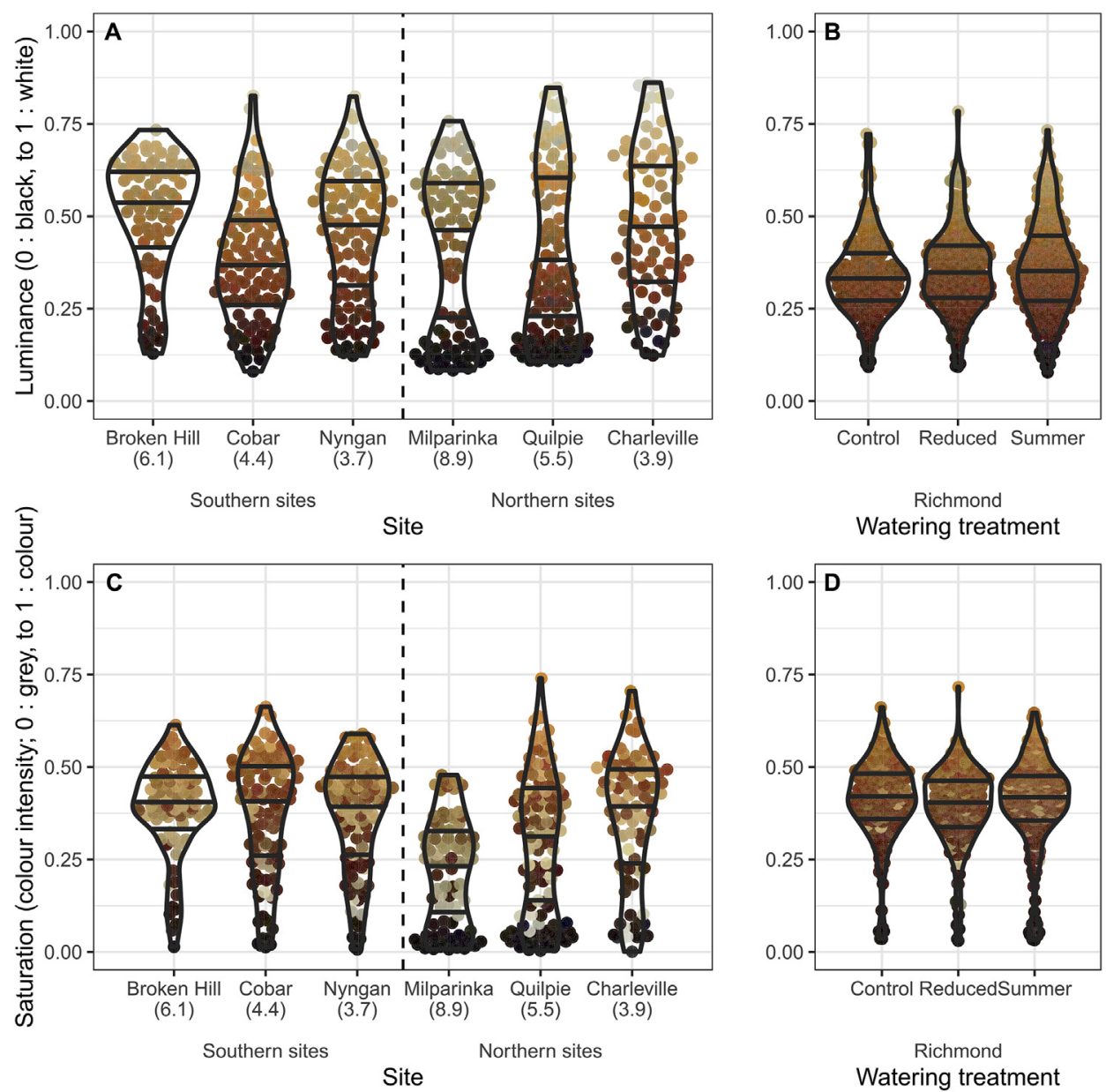

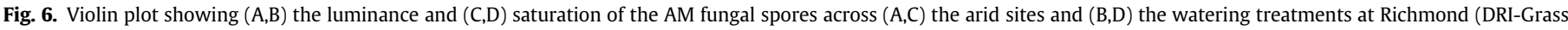

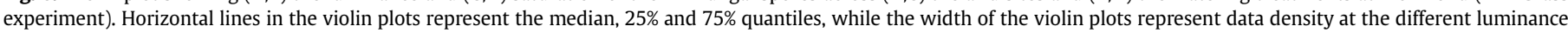

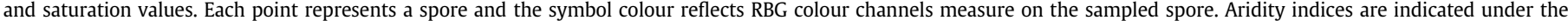
names of the arid sites.

(slope $=0.31, P=0.08$; Fig. 9E). However, this relationship was not observed when evaluating community-averaged luminance (linear model; $P=0.12$, Fig. 9D) or saturation (linear model; $P=0.41$, Fig. 9F) as predictors of average melanin content per unit of spore area. Community-averaged values of black for sampled spores were not associated with melanin content, regardless of whether melanin was calculated on a per spore (linear model; $P=0.25$, Fig. 9A) or per spore area basis (linear model; $P=0.35$, Fig. 9B).

\section{Discussion}

\subsection{Biogeography of AM fungal spore traits}

We expected rainfall to be a limiting factor at the arid sites shaping spore size. We hypothesised that if small spores are more prone to dormancy and predominated in drier environments, it may suggest dormancy as an important strategy to survive stressful periods until conditions become favourable for germination (dormancy hypothesis). Conversely, if larger spores were more abundant in drier environments, it may indicate that nutrients and water reserves within the spore are required to survive and to germinate under stressful conditions (storage hypothesis). However, we found little evidence that spore size was associated with the aridity gradient. Despite this, we cannot exclude spore size as a potentially relevant spore trait responding to rainfall amounts. We did observe that spores in the largest size class were more frequently observed in Richmond compared to arid sites, and that the smallest spores were observed at the arid sites, where annual rainfall is on average 1.8-3.7 times lower than in Richmond. We speculate that drier environments may limit the range of spore size to smaller spores, hinting towards the dormancy hypothesis as a survival strategy in arid environments. However, we acknowledge that these observations are based on a comparison between only a single mesic site (Richmond) and the arid sites. In contrast, it is noteworthy that Davison et al. (2018) found species producing larger spores on islands and suggested that large-spored taxa may be more tolerant to environmental stress. Evaluating spore size in communities from numerous sites with a wider range of rainfall amounts is required to better understand how rainfall shapes spore size.

Spore size was related to the latitude of the site, suggesting that other abiotic conditions might also influence the distribution of this trait. While soil properties may shape spore size, and we found that soil texture and nutrients varied across sites, they do not appear to be related to the latitude of the site (Table S1). However, our northern sites have a higher mean annual temperature and possibly more variable rainfall between years, and communities at those sites had smaller spores, on average, than southern sites. Therefore, we propose that dormancy may also be a survival strategy in communities in warmer climates and/or climates with more 

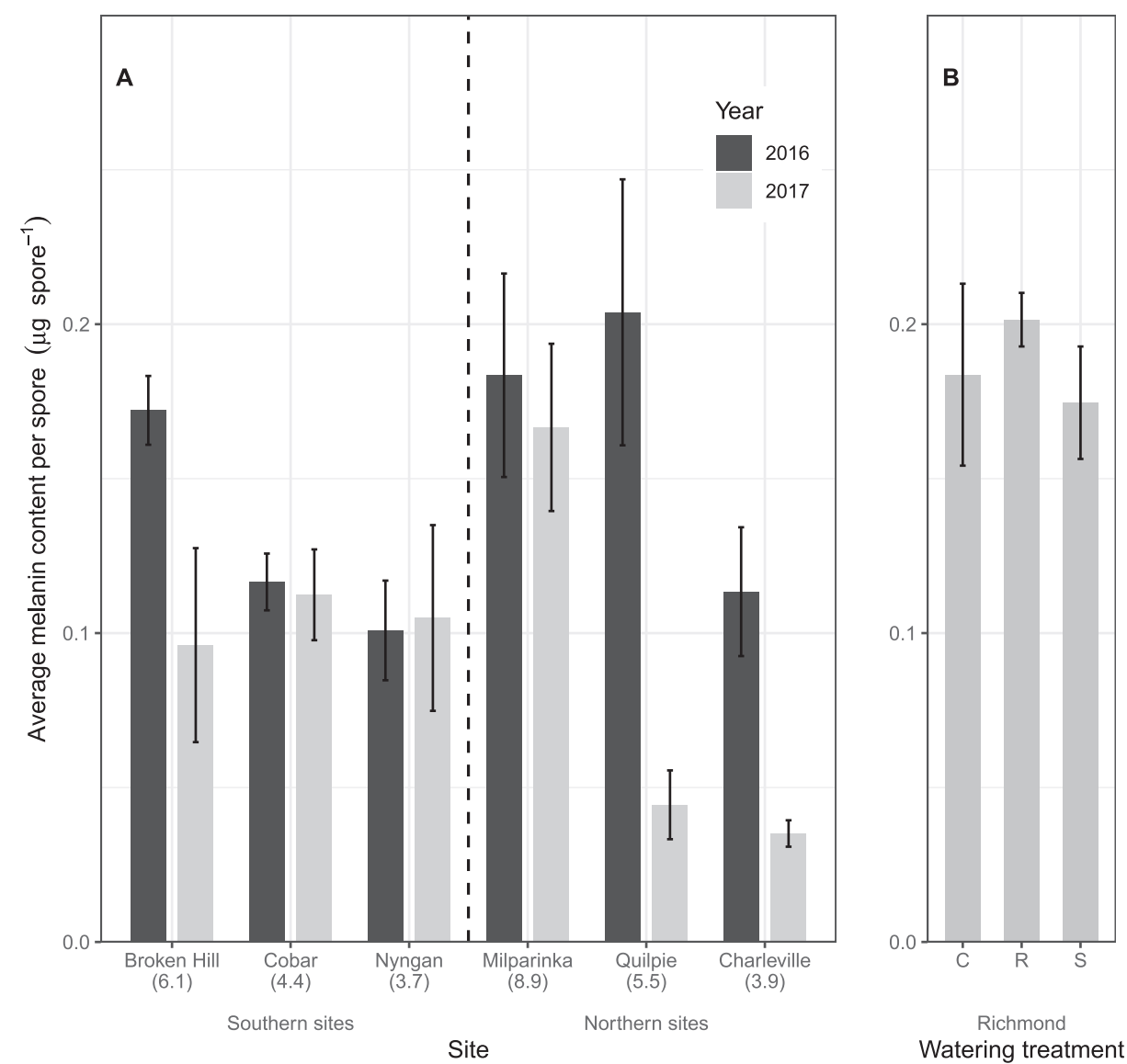

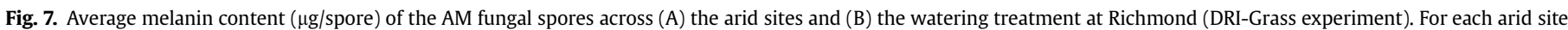

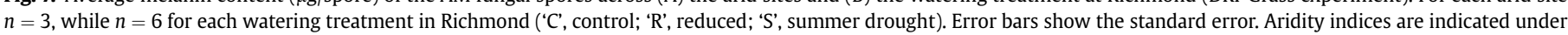
the names of the arid sites.

Table 1

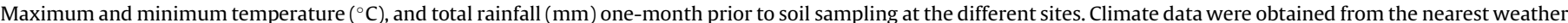

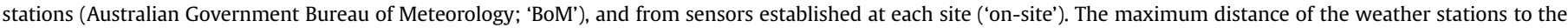
sampling sites is $50 \mathrm{~km}$. Sensors established at each arid site started collecting weather data after the first sampling date.

\begin{tabular}{|c|c|c|c|c|c|}
\hline Site & Source & Sampling year & Rainfall (mm) & Temperature maximum $\left({ }^{\circ} \mathrm{C}\right)$ & Temperature minimum $\left({ }^{\circ} \mathrm{C}\right)$ \\
\hline \multirow[t]{3}{*}{ Broken Hill } & BoM & 2016 & 99.4 & 17.8 & 7.1 \\
\hline & & 2017 & 0 & 40.5 & 20.9 \\
\hline & on-site & 2017 & 2.4 & 32.5 & 18.6 \\
\hline \multirow[t]{3}{*}{ Cobar } & BoM & 2016 & 143 & 18 & 6.4 \\
\hline & & 2017 & 21 & 39.3 & 22.3 \\
\hline & on-site & 2017 & 12.4 & 34 & 19.2 \\
\hline \multirow[t]{3}{*}{ Nyngan } & BoM & 2016 & 65.4 & 19.9 & 8.5 \\
\hline & & 2017 & 53.6 & 36 & 23.2 \\
\hline & on-site & 2017 & 83.2 & 31.4 & 18.6 \\
\hline \multirow[t]{3}{*}{ Milparinka } & BoM & 2016 & 14.6 & 25.5 & 12 \\
\hline & & 2017 & 0.8 & 43 & 23.5 \\
\hline & on-site & 2017 & 1.2 & 35.6 & 20.1 \\
\hline \multirow[t]{3}{*}{ Quilpie } & BoM & 2016 & 104.2 & - & - \\
\hline & & 2017 & 0 & - & - \\
\hline & on-site & 2017 & 0.4 & 35.8 & 22.4 \\
\hline \multirow[t]{3}{*}{ Charleville } & BoM & 2016 & 127.8 & 23.2 & 11.8 \\
\hline & & 2017 & 13.8 & 38.6 & 26.9 \\
\hline & on-site & 2017 & 12.6 & 34.9 & 18.3 \\
\hline
\end{tabular}

variable rainfall.

Despite the range of spore size being lower in arid sites, we found high variability in spore size within each site. Here, we studied trait variation at a community-level, and therefore were unable to evaluate intra- and inter-specific trait variation. Evaluating the range of spore size within species will be important to determine whether this high variability is also present within each species or whether these species can produce smaller spores in stressful environments. In addition, inter-specific variation can inform whether dry environments may select for smaller sporesized species. Nevertheless, this high variability in spore size may be the result of trade-offs between the role of spore size in spore 

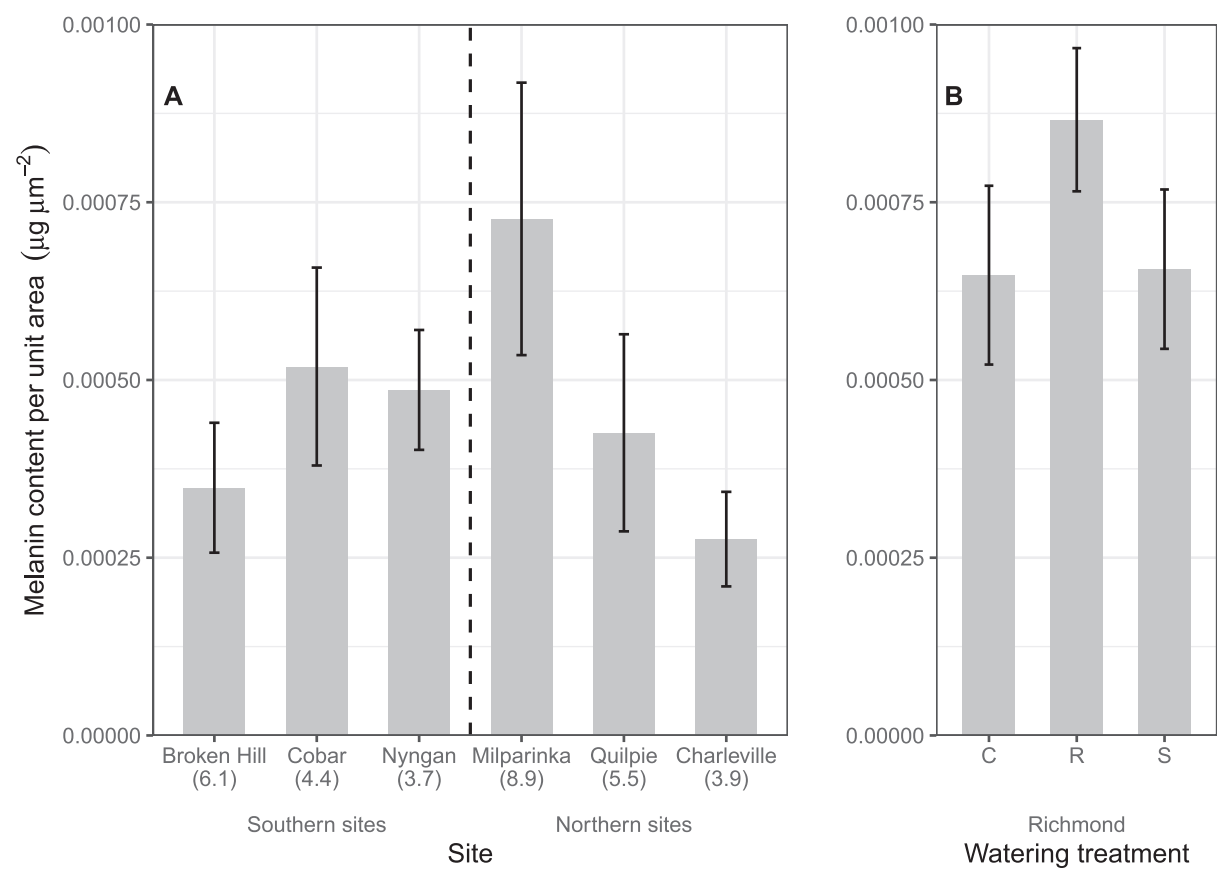

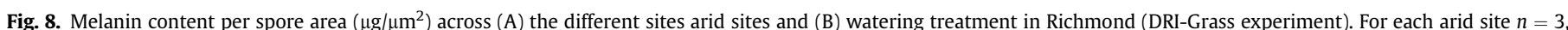

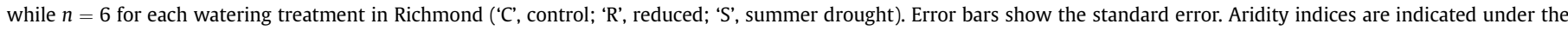
names of the arid sites.

survival and other aspects of their life history. In basidiomycetes, spore size also affects dispersal (Hussein et al., 2013); therefore, we might expect a trade-off between the ability of AM fungal spores to survive and to disperse, as well as a trade-off between spore size and the number of spores produced (Aguilar-Trigueros et al., 2019).

Contrary to our expectations, we found no evidence supporting our prediction of lower spore densities in AM fungal communities sampled from more arid sites. In contrast, others have found a negative relationship between rainfall amounts and spore abundance (Liu et al., 2009; Antoninka et al., 2015). While Antoninka et al. (2015) suggested that spore decomposition may be faster in wetter environments, Liu et al. (2009) considered that since spores are persistent structures, spore production may increase in drier environments to improve survival. Differences in spore densities across arid sites may be the result of changes in the number of spores produced, survival rates or both, and evaluating this requires studying sporulation events and the abundance of spores as well as their germination rates from individual species. For example, Juniper and Abbott (2006) demonstrated that the percentage of germinating AM fungal spores under different salinity levels differed between species, and numerous studies have evaluated how spore abundance varies at the species level in relation to environmental stress (reviewed in Augé, 2001; and i.e. Sun et al., 2013; Silva et al., 2014; Guillén et al., 2019). Studying reproductive output, viability and stress tolerance at the species level is necessary to provide more insight into whether environmental stress selects for specific life history strategies in AM fungi.

Because of its protective properties, we expected melanin concentration to be higher in AM fungal spores sampled from drier environments. Our results support this hypothesis. However, this relationship may be more complex since we did not find any association between melanin content and rainfall amounts in the month prior to sampling. This suggests that, in the short term, this trait may respond to other environmental factors as melanin provides protection against extreme temperatures, enzymatic lysis and UV light (reviewed in Butler and Day, 1998). AM fungal spores can also become darker as they mature (e.g. Claroideoglomus etunicatum, invam.wvu.edu; Morton and Bentivenga, 1994; Stürmer and Morton, 1999, 1997); therefore, sporulation events prior to sampling could be, in part, associated with the decrease in melanin content observed in some spore communities in 2017. More research on how environmental variation influences the phenology of AM fungal spore traits is needed.

Despite the observed increase in average melanin content in drier environments, there was a large range of spore colours at all locations. This included a higher proportion of both light and dark spores in more arid sites. We would not expect communities from arid sites to have a high proportion of light spores if pigments are responsible for protection against stressful environments until the return of favourable conditions for germination (Ruiz-Herrera, 2012). However, differences in time to spore germination exist among AM fungal species (Tommerup, 1985, 1983), and in basidiospores it has been speculated that light spores may germinate quickly, which could be an important trait in habitats with ephemeral growing seasons (Halbwachs and Bässler, 2015). This is the case in our arid sites, where plant-growing seasons are determined by rainfall events, the occurrence of which is unpredictable and highly variable between years. Therefore, producing both light AM fungal spores (that are able to quickly germinate and colonise a host after a rainfall event) and dark spores (protected from stressful environments until conditions are favourable for germination) may be two contrasting successful life history strategies in arid environments.

We expected that colour metrics would indicate the melanin content in spores but found that luminance and the saturation were weakly correlated with melanin content. The colorimetric assay used to quantify melanin was originally designed for abundant fungal hyphae produced in Petri dishes. Further adjustment or development of a more accurate test to measure melanin content in spores may result in a stronger relationship with colour metrics. In addition, we used community-averaged data to evaluate this relationship, which possibly masked correlations because of noise 

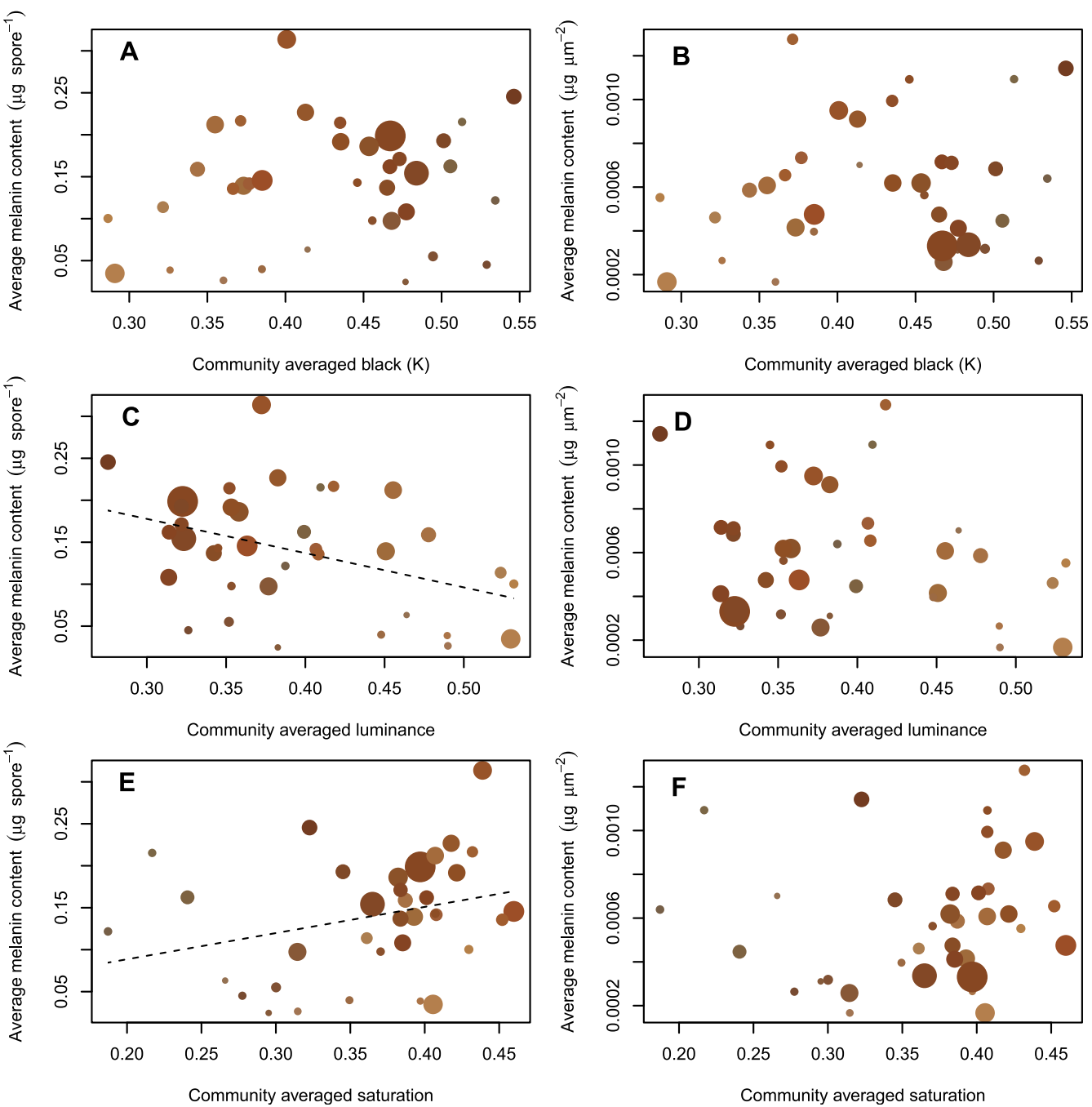

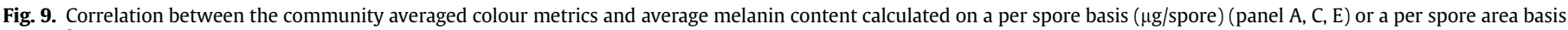

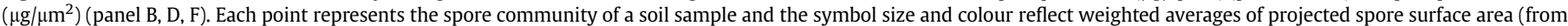
16236 to $77768 \mu \mathrm{m}^{2}$ ) and RBG colour channels measure on the sampled spore community. Dashed lines show the slope of the significant linear correlations.

resulting from inter- and intra-specific variation. In addition, spores with high saturation (yellow, orange and red) could contain high levels of other pigments such as carotenoids and their derivatives (reviewed in Ruiz-Herrera, 2012), which we did not evaluate in this study. Their function in the fungal cell wall is still unknown and their relationship with rainfall remains to be tested.

The plant community and host identity can influence spore diversity and the spore abundance of certain AM fungal species (e.g. Johnson et al., 1992; Bever et al., 1996), and thus result in an effect on traits at the community level. Collecting soil samples in the rhizosphere of the same plant species (Guillén et al., 2019) or phylogenetically related plants (Chaudhary et al., 2014) across all sites may limit the possible effect of host specificity. Although we did not take vegetation into account in this study, the vegetation and dominant species present at each arid site were very different (Table S1). Therefore, we can expect that plant community could have influenced the AM fungal community, and in turn the community-level spore traits.

\subsection{Trait responses under experimentally altered rainfall}

A previous study at the DRI-Grass experiment in Richmond showed that changes in rainfall patterns had a small but significant effect on AM fungal community composition after approximately two years (Deveautour et al., 2018; Deveautour et al., 2019). Here, we found no evidence that changes in the rainfall regimes over 22 months resulted in communities differing in spore traits. We chose this sampling date to assess spore traits due to the large differences in soil moisture between watering treatments observed at the time (Fig. S1). The lack of trait variation in our study may be the result of frequent dispersal among plots of different treatments (minimum distance between plots was $2 \mathrm{~m}$ ), possibly overwhelming treatment effects. In addition, 22 months might not be sufficient time for selection to act on the community and to observe shifts in the distribution of the traits studied here.

\subsection{Future directions for trait relationships and variation in relation to rainfall}

Investigation of other traits may provide additional insight into AM fungal responses to variation in rainfall. Cell wall components such as chitin can be important for the survival of the spores in stressful environments (Merzendorfer, 2011). Mature AM fungal spores differ in their number of wall layers (Peterson et al., 2004), 
which also can be expected to play a role in spore protection. Another variable feature in AM fungal spores is their shape (Bever and Morton, 1999; Souza, 2015), which is hypothesised to influence spore survival because of the relationship between their volume relative to the surface area exposed to a stressful environment (Halbwachs and Bässler, 2015). Traits associated with AM fungal structures other than spores also remain to be explored, such as hyphal hydrophobicity, diameter and colouration (also see AguilarTrigueros et al. 2015).

Our study aimed to identify AM fungal traits associated with variation in aridity to inform future work into their life history and assembly processes. Further work should attempt to quantify traits from cultures derived from individual isolated spores in order to evaluate intra- and inter-specific trait variation under controlled environments. Such information, when combined with species identifications in natural environments, will allow us to relate traits to species performance under different environments and better understand the drivers of AM fungal biogeography.

\section{Data availability}

All data have been archived in Figshare (https://doi.org/10.6084/ m9.figshare.9611513.v1), and scripts and data can be accessed at https://bitbucket.org/Coline_Dev/biogeoamfspore_traits/.

\section{Authors contribution}

$\mathrm{CD}, \mathrm{AEB}$ and JRP conceived the study. UNN, MMB, JC and SB identified locations for the arid sites and collected samples. SAP and UNN established the experimental platform in Richmond (DRIGrass) and CD, JRP and AEB collected samples. MMB calculated aridity indices. $C D$ performed all spore measurements with assistance from CM, and AG identified the spores. CD and JRP performed the data analysis and interpretation. CD wrote the manuscript with input from JRP. All authors contributed to manuscript revisions.

\section{Acknowledgements}

This work was supported by grants from the Australian Research Council to JRP (DP140103936) and UNN (DP140103936) and the Hermon Slade Foundation to SAP. AEB received support from the OECD Co-operative Research Programme Secretariat and Trade and Agriculture Directorate, the Stapledon Memorial Trust Travelling Fellowship, the Hawkesbury Institute for the Environment Research Exchange Program, the Royal Entomological Society Outreach Fund, a British Ecological Society Grant, and the Scottish Government Rural and Environment Science and Analytical Services Division (2016-2021 Work 533 Packages 1.3, 2.1, and 2.3). AG received support from the University of Valencia (UV-INV_PREDOC15-265696 and INV18-01-14-01). We thank Burhan Amiji for help with field work and two anonymous reviewers for comments on this manuscript. We also thank anonymous reviewers for helpful and constructive comments that improved the quality of the manuscript.

\section{Supplementary data}

Supplementary data to this article can be found online at https://doi.org/10.1016/j.funeco.2019.100899.

\section{References}

Aguilar-Trigueros, C.a., Powell, J.R., Anderson, I.C., Antonovics, J., Rillig, M.C., 2014. Ecological understanding of root-infecting fungi using trait-based approaches. Trends Plant Sci. 19, 432-437. https://doi.org/10.1016/j.tplants.2014.02.006.
Aguilar-Trigueros, C.A., Hempel, S., Powell, J.R., Anderson, I.C., Antonovics, J., Bergmann, J., Cavagnaro, T.R., Chen, B., Hart, M.M., Klironomos, J., Petermann, J.S., Verbruggen, E., Veresoglou, S.D., Rillig, M.C., 2015. Branching out: towards a trait-based understanding of fungal ecology. Fungal Biol. Rev. 29 34-41. https://doi.org/10.1016/j.fbr.2015.03.001.

Aguilar-Trigueros, C.A., Hempel, S., Powell, J.R., Cornwell, W.K., Rillig, M.C., 2019 Bridging reproductive and microbial ecology: a case study in arbuscular mycorrhizal fungi. ISME J. 13, 873-884. https://doi.org/10.1038/s41396-0180314-7.

Antoninka, A.J., Ritchie, M.E., Johnson, N.C., 2015. The hidden Serengeti-mycorrhizal fungi respond to environmental gradient. Pedobiologia 58, 165-176. https://doi.org/10.1016/j.pedobi.2017.06.004.

Augé, R.M., 2001. Water relations, drought and vesicular-arbuscular mycorrhizal symbiosis. Mycorrhiza 11, 3-42. https://doi.org/10.1007/s005720100097.

Bates, D., Mächler, M., Bolker, B., Walker, S., 2015. Fitting linear mixed-effects models using lme4. J. Stat. Softw. 67, 1-48. https://doi.org/10.18637/jss.v067.i01.

Bever, J.D., Morton, J., 1999. Heritable variation and mechanisms of inheritance of spore shape within a population of Scutellospora pellucida an arbuscular mycorrhizal fungus. Am. J. Bot. 86, 1209-1216.

Bever, J.D., Morton, J.B., Antonovics, J., Schultz, P.A., 1996. Host-dependent sporulation and species diversity of arbuscular mycorrhizal fungi in a mown grassland. Br. Ecol. Soc. 84, 71-82.

Butler, Lachance, 1986. Quantitative binding of azure A to melanin black yeast. Phaeococcomyces 170, 166-170.

Butler, M., Day, A., 1998. Fungal melanins: a review. Can. J. Microbiol. 44, 1115-1136. https://doi.org/10.1139/w98-119.

Chagnon, P.L., Bradley, R.L., Maherali, H., Klironomos, J.N., 2013. A trait-based framework to understand life history of mycorrhizal fungi. Trends Plant Sci. 18, 484-491. https://doi.org/10.1016/j.tplants.2013.05.001.

Chaudhary, V.B., O'Dell, T.E., Rillig, M.C., Johnson, N.C., 2014. Multiscale patterns of arbuscular mycorrhizal fungal abundance and diversity in semiarid shrublands. Fungal Ecol 12, 32-43. https://doi.org/10.1016/j.funeco.2014.06.003.

Cordero, R.J.B., Robert, V., Cardinali, G., Arinze, E.S., Thon, S.M., Casadevall, A., 2018 Impact of yeast pigmentation on heat capture and latitudinal distribution. Curr. Biol. 28, 1-8. https://doi.org/10.1016/j.cub.2018.06.034.

Davet, P., 2004. Microbial Ecology of the Soil and Plant Growth. Science Publishers, Enfield, NH.

Davison, J., Moora, M., Öpik, M., Ainsaar, L., Ducousso, M., Hiiesalu, I., Jairus, T., Johnson, N., Jourand, P., Kalamees, R., Koorem, K., Meyer, J.Y., Püssa, K., Reier, Ü., Pärtel, M., Semchenko, M., Traveset, A., Vasar, M., Zobel, M., 2018. Microbial island biogeography: isolation shapes the life history characteristics but not diversity of root-symbiotic fungal communities. ISME J. 1-14. https://doi.org/ 10.1038/s41396-018-0196-8.

De Valpine, P., Harte, J., 2001. Plant responses to experimental warming in a montane meadow. Ecology 82, 637-648.

Deveautour, C., Donn, S., Power, S.A., Bennett, A.E., Powell, J.R., 2018. Experimentally altered rainfall regimes and host root traits affect grassland arbuscula mycorrhizal fungal communities. Mol. Ecol. 27, 2152-2163. https://doi.org/ 10.1111/mec.14536.

Deveautour, C., Power, S.A., Barnett, K.L., Ochoa-Hueso, R., Donn, S., Bennett, A.E. Powell, J.R., 2019. Temporal dynamics of mycorrhizal fungal communities and co-associations with grassland plant communities following experimenta manipulation of rainfall. J. Ecol. 1-13. https://doi.org/10.1111/1365-2745.13267.

Fernandez, C.W., Koide, R.T., 2013. The function of melanin in the ectomycorrhizal fungus Cenococcum geophilum under water stress. Fungal Ecol 6, 479-486. https://doi.org/10.1016/j.funeco.2013.08.004.

Fick, S.E., Hijmans, R.J., 2017. WorldClim 2: new 1-km spatial resolution climate surfaces for global land areas. Int. J. Climatol. 37, 4302-4315. https://doi.org/ $10.1002 /$ joc. 5086

Fox, J., Weisberg, S., 2011. An R Companion to Applied Regression.

Guillén, A., Mesquita-Joanes, F., Peris, J.B., Arrillaga, I., 2019. Effects of environmental and temporal factors on Glomeromycotina spores in sand dunes along the Gulf of Valencia (Spain). Fungal Ecol 40, 127-139. https://doi.org/10.1016/ j.funeco.2018.07.001.

Halbwachs, H., Bässler, C., 2015. Gone with the wind - a review on basidiospores of lamellate agarics. Mycosphere 6, 78-112. https://doi.org/10.5943/mycosphere/ $6 / 1 / 10$.

Hanbury, A., 2003. Circular statistics applied to colour images. 8th Comput. Vis. Winter Work. 91, 53-71.

Hart, M.M., Zaitsoff, P.D., van der Heyde, M., Pither, J., 2016. Testing life history and trait-based predictions of AM fungal community assembly. Pedobiologia 59 203-213. https://doi.org/10.1016/j.pedobi.2016.06.001.

Henson, J., Butler, M.J., Day, A., 1999. The dark side of the mycelium: melanins of phytopathogenic fungi. Annu. Rev. Phytopathol. 37, 447-471.

Hussein, T., Norros, V., Hakala, J., Petäjä, T., Aalto, P.P., Rannik, Ü., Vesala, T. Ovaskainen, O., 2013. Species traits and inertial deposition of fungal spores. J. Aerosol Sci. 61, 81-98. https://doi.org/10.1016/j.jaerosci.2013.03.004.

International culture collection of (vesicular) arbuscular mycorrhizal fungi [WWW Document], 2018. https://invam.wvu.edu/. https://invam.wvu.edu/.

IPCC, 2014. Climate Change 2014: Synthesis Report. Contribution of Working Groups I, II and III to the Fifth Assessment Report of the Intergovernmental Panel on Climate Change, IPCC. IPCC, Geneva, Switzerland. https://doi.org $10.1017 /$ CBO9781107415324.

Jacobson, E.S., 2000. Pathogenic roles for fungal melanins. Clin. Microbiol. Rev. 13, 708-717. https://doi.org/10.1128/CMR.13.4.708-717.2000. 
Jeffrey, S.J., Jeffrey, S.J., Carter, J.O., Moodie, K.B., Beswick, A.R., 2001. Using spatial interpolation to construct a comprehensive archive of Australian climate data. Environ Model Softw Using spatial interpolation to construct a comprehensive archive of Australian climate data 16, 309-330. https://doi.org/10.1016/S13648152(01)00008-1.

Johnson, N.C., Tilman, D., Wedin, D., 1992. Plant and soil controls on mycorrhizal fungal communities. Ecology 73, 2034-2042.

Juniper, S., Abbott, L.K., 2006. Soil salinity delays germination and limits growth of hyphae from propagules of arbuscular mycorrhizal fungi. Mycorrhiza 16 371-379. https://doi.org/10.1007/s00572-006-0046-9.

Li, X., Zhu, T., Peng, F., Chen, Q., Lin, S., Christie, P., Zhang, J., 2015. Inner Mongolian steppe arbuscular mycorrhizal fungal communities respond more strongly to water availability than to nitrogen fertilization. Environ. Microbiol. 17, 3051-3068. https://doi.org/10.1111/1462-2920.12931.

Lin, D., Xia, J., Wan, S., 2010. Climate warming and biomass accumulation of terrestrial plants : a meta-analysis. New Phytol. 188, 187-198. https://doi.org/ 10.1111/j.1469-8137.2010.03347.x.

Liu, Y., He, L., An, L., Helgason, T., Feng, H., 2009. Arbuscular mycorrhizal dynamics in a chronosequence of Caragana korshinskii plantations. FEMS Microbiol. Ecol. 67, 81-92. https://doi.org/10.1111/j.1574-6941.2008.00597.x.

Martínez-García, L.B., de Dios Miranda, J., Pugnaire, F.I., 2012. Impacts of changing rainfall patterns on mycorrhizal status of a shrub from arid environments. Eur. J. Soil Biol. 50, 64-67. https://doi.org/10.1016/j.ejsobi.2011.12.005.

Merzendorfer, H., 2011. The cellular basis of chitin synthesis in fungi and insects: common principles and differences. Eur. J. Cell Biol. 90, 759-769. https:/ doi.org/10.1016/j.ejcb.2011.04.014.

Morton, J.B., Bentivenga, S.P., 1994. Levels of diversity in endomycorrhizal fung (Glomales, Zygomycetes) and their role in defining taxonomic and nontaxonomic groups. Plant Soil 159, 47. https://doi.org/10.1007/BF00000094.

Oksanen, J. Blanchet, F.G., Friendly, M., Kindt, R., Legendre, P., McGlinn, D. Minchin, P.R., O'Hara, R.B., Simpson, G.L., Solymos, P., Stevens, M.H.H., Szoecs, E. Wagner, H., 2018. Vegan: Community Ecology Package.

Peterson, R., Massicotte, H.B., Melville, L.H., 2004. Mycorrhizas Anatomy and Cell Biology. NRC Research Press, Ottawa, Ont.

Power, S.A., Barnett, K.L., Ochoa-hueso, R., Facey, S.L., Gibson-forty, E.V.J., Hartley, S.E., Nielsen, U.N., Tissue, D.T., Johnson, S.N., 2016. DRI-Grass : a new experimental platform for addressing grassland ecosystem responses to future precipitation scenarios in south-east Australia. Front. Plant Sci. 7, 1-14. https:// doi.org/10.3389/fpls.2016.01373.

R Core Team, 2018. R: A Language and Environment for Statistical Computing.

Ruiz-Herrera, J., 2012. Fungal Cell Wall : Structure, Synthesis, and Assembly, 2nd. editi. CRC Press, Boca Raton, FL.

Silva, I.R. Da, Mello, C.M.A. De, Ferreira Neto, R.A., Silva, D.K.A. Da, Melo, A.L. De, Oehl, F., Maia, L.C., 2014. Diversity of arbuscular mycorrhizal fungi along an environmental gradient in the Brazilian semiarid. Appl. Soil Ecol. 84, 166-175. https://doi.org/10.1016/j.apsoil.2014.07.008.

Souza, T., 2015. Handbook of Arbuscular Mycorrhizal Fungi. Springer International Publishing, Switzerland. https://doi.org/10.1007/978-3-319-24850-9.

Staddon, P.L., Thompson, K., Jakobsen, I., Grime, J.P., Askew, A.P., Fitter, A.H., 2003. Mycorrhizal fungal abundance is affected by long-term climatic manipulations in the field. Glob. Chang. Biol. 9, 186-194. https://doi.org/10.1046/j.13652486.2003.00593.x.

Stürmer, S.L., Morton, J.B., 1997. Developmental patterns defining morphological characters in spores of four species in glomus. Mycologia 89, 72-81.

Stürmer, S.L., Morton, J.B., 1999. Taxonomic reinterpretation of morphological characters in Acaulosporaceae based on developmental patterns. Mycologia 91, 849-857.

Sun, X.F., Su, Y.Y., Zhang, Y., Wu, M.Y., Zhang, Z., Pei, K.Q., Sun, L.F., Wan, S.Q. Liang, Y., 2013. Diversity of arbuscular mycorrhizal fungal spore communities and its relations to plants under increased temperature and precipitation in a natural grassland. Chin. Sci. Bull. 58, 4109-4119. https://doi.org/10.1007/ s11434-013-5961-5.

Tommerup, I.C., 1983. Spore dormancy in vesicular-arbuscular mycorrhizal fungi. Trans. Br. Mycol. Soc. 81, 37-45. https://doi.org/10.1016/s0007-1536(83)80201-

Tommerup, I.C., 1985. Inhibition of spore germination of vesicular-arbuscular mycorrhizal fungi in soil. Trans. Br. Mycol. Soc. 85, 267-278. https://doi.org/ 10.1016/s0007-1536(85)80188-1.

Treseder, K.K., Lennon, J.T., 2015. Fungal traits that drive ecosystem dynamics on land. Microbiol. Mol. Biol. Rev. 79, 243-262. https://doi.org/10.1128/ MMBR.00001-15.

van Ommen Kloeke, A.E.E, Douma, J.C., Ordoñez J.C, Reich, PB, van Bodegom, P.M. 2012. Global quantification of contrasting leaf life span strategies for deciduous and evergreen species in response to environmental conditions. Glob. Ecol. Biogeogr. 21, 224-235. https://doi.org/10.1111/j.1466-8238.2011.00667.x. 